\title{
cAMP activates the generation of reactive oxygen species and inhibits the secretion of IL-6 in peripheral blood mononuclear cells from type 2 diabetic patients
}

\author{
Camila Armond Isoni,' Érica Abreu Borges,' Clara Araújo Veloso,' Rafael Teixeira Mattos,' Miriam Martins Chaves ${ }^{2}$ \\ and José Augusto Nogueira-Machado',*
}

'Núcleo de Pós-Graduação e Pesquisa; Hospital Santa Casa de Belo Horizonte; Belo Horizonte; Minas Gerais, Brasil; ²Departamento de Bioquímica e Imunologia; Universidade Federal de Minas Gerais; Belo Horizonte; Minas Gerais, Brazil

Key words: ROS, IL-6, cAMP, diabetes, peripheral blood mononuclear cells

\begin{abstract}
Peripheral blood mononuclear cells (PBMNC) from patients with type 2 diabetes (DM2) have generated higher levels of reactive oxygen species (ROS) that were higher than those in cells from healthy individuals. In the presence of a cAMPelevating agent, ROS production was significantly activated in PBMNC from DM2 patients but it was inhibited in cells from healthy subjects. Higher levels of IL-6 has been detected in the supernatant of PBMNC cultures from DM2 patients in comparison with healthy controls. When cells were cultured in the presence of a CAMP-elevating agent, the level of IL-6 decreased has by $46 \%$ in the supernatant of PBMNC from DM2 patients but it remained unaltered in controls. No correlations between ROS and IL-6 levels in PBMNC from DM2 patients or controls have been observed. Secretions of IL-4 or IFN by PBMNC from patients or controls have not been affected by the elevation of CAMP. cAMP elevating agents have activated the production of harmful reactive oxidant down modulated IL-6 secretion by these cells from DM2 patients, suggesting an alteration in the metabolic response possibly due to hyperglicemia. The results suggest that cAMP may play an important role in the pathogenesis of diabetes.
\end{abstract}

\section{Introduction}

Chronic low-grade inflammation and activation of the innate immune system are closely involved in the pathobiochemical and immunopathogenesis of type 2 diabetes mellitus (DM2). ${ }^{1}$ Both acute and chronic hyperglycemias determine a pro-inflammatory state. A single hyperglycaemia-induced process of overproduction of reactive oxygen species (ROS) seems to be important in the activation of all of the other pathways involved in the pathogenesis of diabetic inflammatory complications. ${ }^{2}$ Additionally, acutephase circulating inflammatory responses, of which interleukin 6 (IL-6) appears to be the major cytokine mediator, are strong predictors of the development of DM2, and it is believed that cytokine production may be mediated by ROS. ${ }^{1}$ Hyperglycaemia produces alterations to various signalling pathways resulting in the modulation of cellular reactivity. ${ }^{3-5}$ In this context, cAMP is an important second messenger of cellular activation. The presence of cAMP-elevating agents has been shown to inhibit IL-2 and gamma-interferon (IFN $\gamma$ ), but not as to IL-4 and IL-5, in Jurkat cells. ${ }^{6}$ Moreover, cAMP potentiates IL-6 production in neuronal cells and inhibits such production in adipocytes. ${ }^{78}$ The intracellular level of cAMP is elevated following activation of adenyl cyclase by prostaglandin $\mathrm{E}_{2}$ (PGE2). . Interestingly, PGE2 is produced by inflammatory cells, ${ }^{9}$ and the levels of PGE2 are significantly elevated in a diabetic population with nephropathy and retinopathy. ${ }^{10,11}$ In diabetic rats, the level of PGE2 is increased by hyperglycaemia. ${ }^{12}$

We have previously suggested that an increase in the level of cAMP inhibits ROS and NO production in granulocytes from healthy subjects, but activates their generation in cells from DM2 patients. ${ }^{13}$ In the present study we have investigated the effect of a cAMP-elevating agent on ROS, IL-4, IL-6 and IFN $\gamma$ production by peripheral blood mononuclear cells (PBMNC) from DM2 patients in addition to evaluate possible correlations between ROS generation and cytokine secretion by these cells.

\section{Results}

Patients. Biochemical parameters of type 2 diabetic patients and healthy control were compared and the results are shown in the Table 1. Fasting glucose level was significantly different $(\mathrm{p}<0.05)$.

Activation of ROS production by cAMP in PBMNC from DM2 patients. The results of the present study revealed that 
Table I. Characteristics of the studied groups

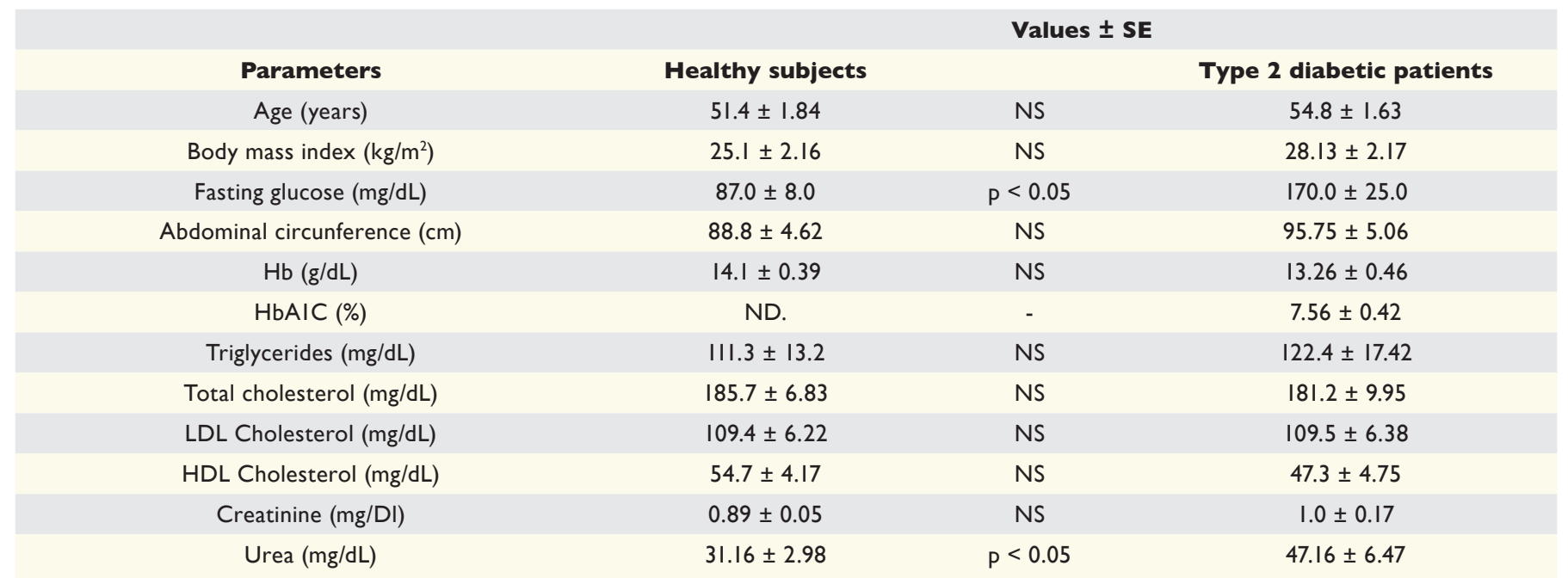

NS: non significant $(p>0.05)$ Only fasting glucose level showed significant difference $(p<0.05)$ when healthy control and type 2 diabetic patients were compared.

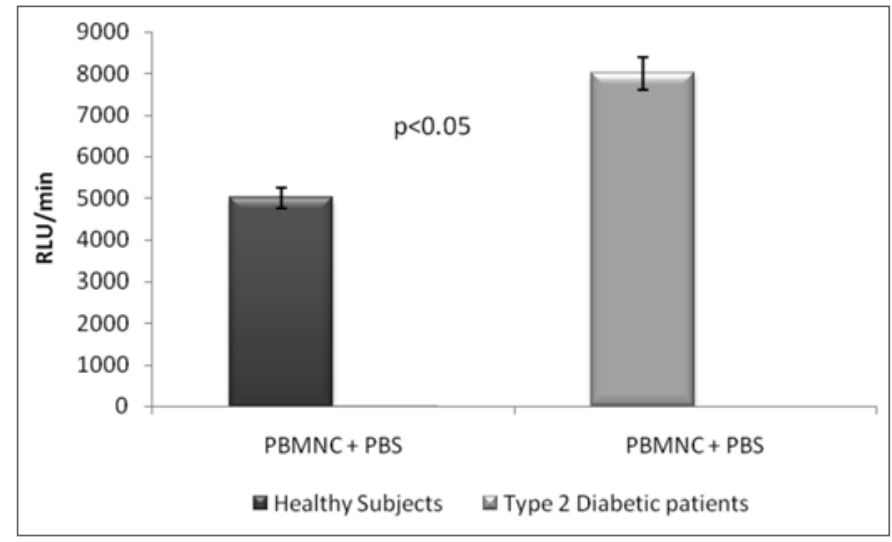

Figure I. Reactive Oxygen species (ROS) generation by peripheral blood mononuclear cells from type 2 diabetic patients-PBMNC $=$ peripheral blood mononuclear cells; the values were compared by Student " $t$ " test; $p<0.05$ were considered as significant; $R L U / \mathrm{min}=$ Relative Light Units per minute; $\mathrm{PBS}=$ phosphate buffered saline. ROS production was greater in DM2 than in healthy control. DM2 = type 2 diabetic patients; $\mathrm{PBMNC}=$ peripheral blood mononuclear cells.

the average ROS production by PBMNC derived from DM2 patients (equivalent to $8.4 \pm 1.2$ expressed in RLU/min $\times 10^{-3}$; $n=15)$ was aproximately 1.6 -times greater $(\mathrm{p}<0.05)$ than by PBMNC from healthy individuals $\left(5.0 \pm 0.6 \mathrm{RLU} / \mathrm{min} \times 10^{-3}\right.$; $n=16$ ) (Fig. 1). The ROS production expressed as RLU/min PBMNC and the ratios of ROS generation of ROS by PBMNC in the presence (E) and absence $(\mathrm{C})$ of $10^{-5} \mathrm{M}$ cAMP are shown in the Figures 2 and 3. In the Figure 5 is shown a typical curve of ROS production by PBMNC performed in the absence or in the presence of cAMP. The values of the $\mathrm{E} / \mathrm{C}$ ratios were 1.75 for DM2, patients and 0.58 for healthy subjects (Fig. 3). It appears, therefore, that whilst cAMP induced a significant activation of ROS production by PBMNC from diabetic patients, its presence was inhibitory to ROS generation in healthy controls (Fig. 2).

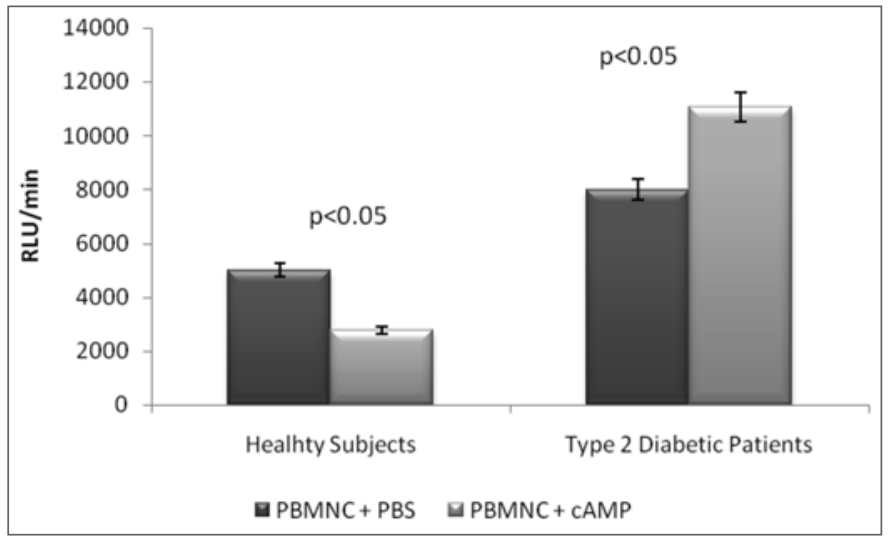

Figure 2. Effect of cyclic AMP (cAMP) on ROS production in PBMNC from type 2 diabetic patients in comparison to healthy subjects. RLU/ $\min =$ Relative Light Units per minutes; PBMNC= Peripheral blood mononuclear cells; The average were compared by Student " $t$ " test and $\mathrm{P}<0.05$ was considered as a significant difference.

Inhibition of IL-6 production by cAMP in PBMNC from DM2 patients. In order to determine whether the observed upregulation of ROS production in PBMNC from DM2 patients was associated with modulation in the production of pro- or anti-inflammatory cytokines, supernatants from PBMNC that had been cultured in the presence or absence of cAMP were assayed for IL-4, IL- 6 and IFN $\gamma$. As can be seen from the results shown in Table 2, PBMNC from DM2 patients produced a significantly $(\mathrm{p}<0.05)$ higher amount of IL-6 $(25.3 \pm 2.88 \mathrm{pg} / \mathrm{ml})$ as compared with cells from healthy subjects $(3.0 \pm 1.2 \mathrm{pg} / \mathrm{ml})$ (Table 2 and Fig. 4). However, in the presence of cAMP, the secretion of IL-6 was significantly inhibited (45.7\%) in DM2 patients but remained unaltered in healthy subjects (Table 2). The levels of IL- 4 and IFN $\gamma$ produced by PBMNC from DM2 patients and healthy controls were not significantly different and were not modulated by the presence of cAMP (Table 2). 
Statistical analyses revealed no correlations between ROS production and levels of IL-4, IL-6 or IFN $\gamma$ (Table 3).

\section{Discussion}

In this study we examined the reactivity of PBMNC from DM2 patients in the presence and absence of a cAMP-elevating agent in comparison with cells from healthy controls. We observed an altered reactivity for ROS and IL-6 production in DM2 patients, whilst IL- 4 and IFN $\gamma$ levels were insensitive to the hyperglycaemia of diabetes and to the intracellular elevation of cAMP.

Diabetes is believed to be an inflammatory disease in which the associated chronic hyperglycaemia is linked with an increase in ROS generation by $\mathrm{PBMNC}^{14}$ Results from the present study confirmed that the production of ROS in PBMNC from DM2 patients is significantly greater than in cells from healthy individuals. It has been suggested that the rise in ROS production is associated with an increase of $\mathrm{p}^{4} 7^{\text {phox }}$, a component of the NADPH-oxidase system. ${ }^{15}$ However, cytokine production may also be mediated by ROS, ${ }^{1}$ and in this context an increase in PGE2 has been reported in vascular complications of diabetes. ${ }^{10}$ Since PGE2 activates adenyl cyclase to form cAMP, a functional relationship between ROS, cAMP and cytokine secretion could be proposed. Mitogen-activated oritein kinases (MAPKs) includes three subgroups of MAPKs identified as extracellular signal-regulated kinase (ERK), p38 MAPK and cJun aminoterminal kinase (JNK). ${ }^{16,17}$ In J774 macrophages, the association between cAMP, NO and IL- 6 was demonstrated, ${ }^{18}$ and ERK and p38 MAPK are involved in the upregulation of gene expression of inducible NO syntase (iNOS) and IL-6. ${ }^{19,20}$ Mitochondrial ROS and IL- 6 activate AMP-activated protein kinses (AMPK) and the effect of IL-6 depends on cAMP. ${ }^{20,21}$

We have previously reported that cAMP increases ROS production in granulocytes from patients with diabetes types 1 and 2 via a PKA-independent signalling pathway. ${ }^{23}$ In the present study, we were able to demonstrate a similar effect of cAMP on PBMNC from DM2 patients, although cAMP inhibited ROS generation in PBMNC from healthy controls (Figs. 2, 3 and 5). It may thus be hypothesised that the hyperglycaemia of diabetes induces an adaptation in the metabolic response of diabetic patients.

In order to investigate the possible association between ROS production and the release of cytokines, we evaluated the production of the anti-inflammatory cytokine IL- 4 and the two pro-inflammatory cytokines IL- 6 and IFN $\gamma$ by PBMNC in the presence and absence of a cAMP-elevating agent. In these experiments, the levels of IL- 4 and IFN $\gamma$ were similar in PBMNC derived from DM2 patients and from healthy controls, both in the presence and absence of cAMP (Table 2, Fig. 4). The results relating to IL-4 are in agreement with those reported from previous studies. ${ }^{24,25}$ More significantly, however, is that the present study revealed an increase in both ROS and IL- 6 production by PBMNC derived from DM2 patients as compared with cells from healthy individuals (Table 2; Fig. 4). Furthermore, intracellular elevation of cAMP induced an inhibition of IL-6 secretion

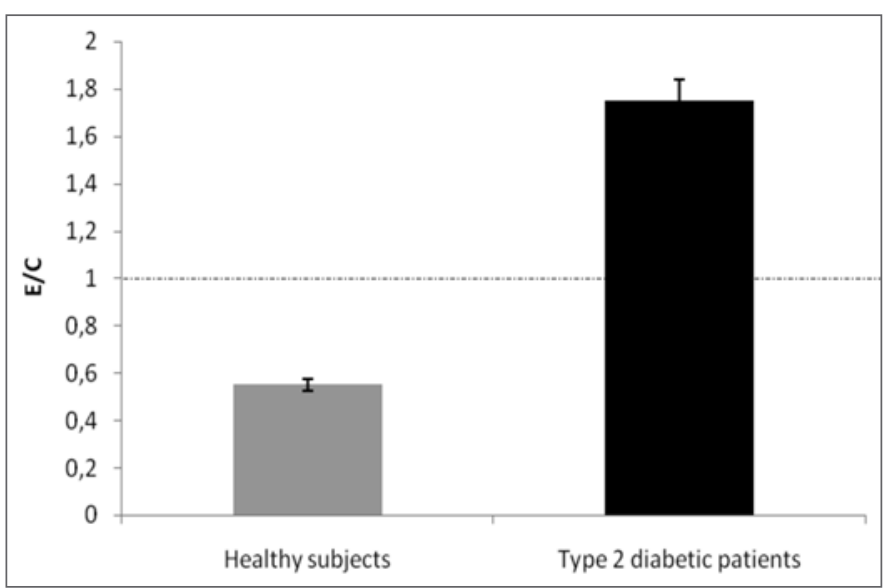

Figure 3. The effect of CAMP on ROS production in PBMNC from DM2 patients and from healthy subjects. The results are expressed in the form of the ratio $E / C$ for individual subjects, where $E$ refers to cells cultured in the presence of CAMP (experiment) and C refers to cells cultured in the absence of the additive (Control). E/C $=[\mathrm{RLU} / \mathrm{min}$ produced by $\mathrm{PBMNC}$ in the presence of $\mathrm{CAMP}] /[\mathrm{RLU} / \mathrm{min}$ produced by PBMNC in the absence of $c A M P] . R L U / m i n=$ Relative Light Units per minutes; $\mathrm{PBMNC}=$ peripheral blood mononuclear cells.

by PBMNC from diabetic patients but it did not modulate IL-6 production by PBMNC from healthy controls. This kind of control of interleukin synthesis has not been observed with either IL- 4 or IFN $\gamma$. IL-6 has previously been shown to modify insulin sensitivity, ${ }^{26}$ whilst an increase in the level of cAMP has been reported to upregulate both IL-1 beta and IL- 6 transcripts. ${ }^{27}$

In spite of the observed increases in ROS and IL- 6 generation by PBMNC derived from DM2 patients, no correlations were observed between ROS and IL-4, IL- 6 or IFN $\gamma$ in any of the experiments performed with cells from DM2 patients or from healthy individuals, either in the presence or absence of cAMP.

cAMP enhances the activity of protein kinase A (PKA) ${ }^{28}$ which activates protein kinase $\mathrm{C}$ (PKC) and p38 MAPK leading to a NFKB activation with consequent induction of inducible nitric oxide synthase (iNOS) and IL-6. ${ }^{18}$

The activation of ROS production by cAMP in PBMNC from DM2 patients, and the concomitant downregulation of IL-6, may suggest a regulatory mechanism in the inflammatory process. We have previously suggested that cAMP modulates ROS production in granulocytes from DM2 patients using a metabolic route PKA-independent, Epac/PKB-dependent. ${ }^{29}$ Izuora et al. ${ }^{10}$ have demonstrated that PGE2 levels did not correlate with the grade of retinopathy, and proposed that the elevation of PGE2 could be regarded as a marker of inflammation associated with microvascular complications. Our present results suggest that elevated ROS production, in association with high levels of IL-6, could be considered as a typical profile of type 2 diabetes as well as suggestive of an active inflammatory response. It is proposed that the intracellular increase of cAMP, which might arise from the elevation of PGE2, could activate ROS production and simultaneous downregulation of IL-6. This may represent a novel type of regulatory mechanism of diabetic inflammation and reinforces previous findings. ${ }^{10}$ 
Table 2. The modulation by cAMP of cytokine production in PBMNC from type 2 diabetic patients and healthy individuals

\begin{tabular}{cccccccc}
\multicolumn{3}{c}{ PBMNC + cAMP } & & PBMNC \\
Cytokines & Healthy subjects & & DM2 patients & Healthy subjects & DM2 patients \\
IL-6 & $3.5 \pm 1.26$ & $\mathrm{P}<0.05^{\mathrm{b}}$ & $14.1 \pm 3.04$ & $3.0 \pm 1.2$ & $\mathrm{P}<0.05^{\mathrm{b}}$ & $25.3 \pm 2.88$ \\
INF $\gamma$ & $6.64 \pm 0.41$ & $\mathrm{~ns}^{\mathrm{b}}$ & $8.75 \pm 1.18$ & $6.39 \pm 0.39$ & $\mathrm{~ns}^{\mathrm{b}}$ & $7.02 \pm 0.51$ \\
IL-4 & $232 \pm 1.63$ & $\mathrm{~ns}^{\mathrm{b}}$ & $231.2 \pm 2.8$ & $239.4 \pm 7.5$ & $\mathrm{~ns}^{\mathrm{b}}$ & $230.6 \pm 2.9$
\end{tabular}

a Mean values \pm SD $(n=9)$; Cytokines quantification was performed by ELISA using supernatant of cultured PBMNC (peripheral blood mononuclear

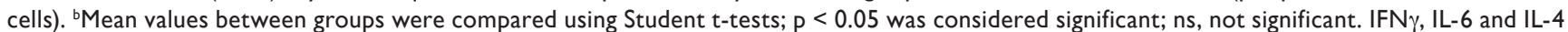
refer to gamma interferon, interleukin 6 and interleukin 4 , respectively.

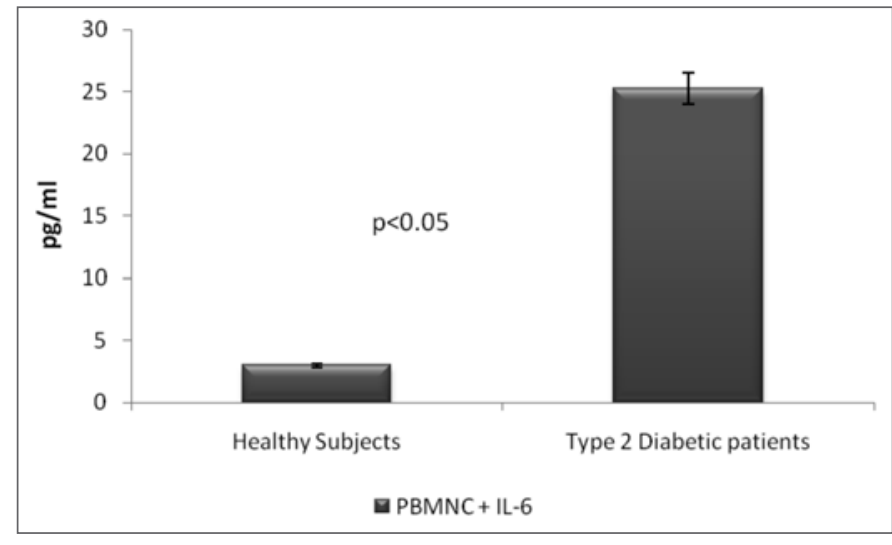

Figure 4. Quantification of IL-6 in supernatant of cultured PBMNC. PBMNC (peripheral blood mononuclear cells) were cultured in RPMI1640 and the culture supernatant, cell-free, was assayed for interleukin 6 (IL-6). Comparison of IL-6 in supernatant of PBMNC from DM2 and Healthy control. Peripheral blood mononuclear cells (PBMNC) were cultured in RPMI-16-40 for $48 \mathrm{~h}$ at $37^{\circ} \mathrm{C}$. The supernatant cell-free was used for quantification of inteleukin 6 (IL-6) in an ELISA commercial kit. The values were compared by Student " $t$ " test and the difference between IL-6 from healthy control and from type diabetic patients (DM2) was significant.

Taken together, our results provide evidences that cAMP may play a prominent role in IL-6 modulation in PBMNC from DM2 patients and, consequently, in the pathogenesis of diabetes.

\section{Materials and Methods}

Details of the project were presented to and approved by the Ethical Committee of the Hospital Santa Casa de Belo Horizonte (Belo Horizonte-MG, Brazil). Appropriate informed consent was obtained from all participants prior to the commencement of the study.

Subjects. Patients suffering from DM2 (diagnosed according to the criteria of the American Diabetes Association) and healthy volunteers, all within the age range of 30-75 years, were recruited from the endocrinology service of the Santa Casa Hospital. Each volunteer was submitted to a detailed physical examination, together with an evaluation of relevant medical history and laboratory data, before being subjected to the study. The levels of fasting plasma glucose were determined to be $170 \pm 25$ and $87 \pm$ $8.0 \mathrm{mg} / \mathrm{dl}$, respectively, for DM2 patients and healthy controls (Table 1).

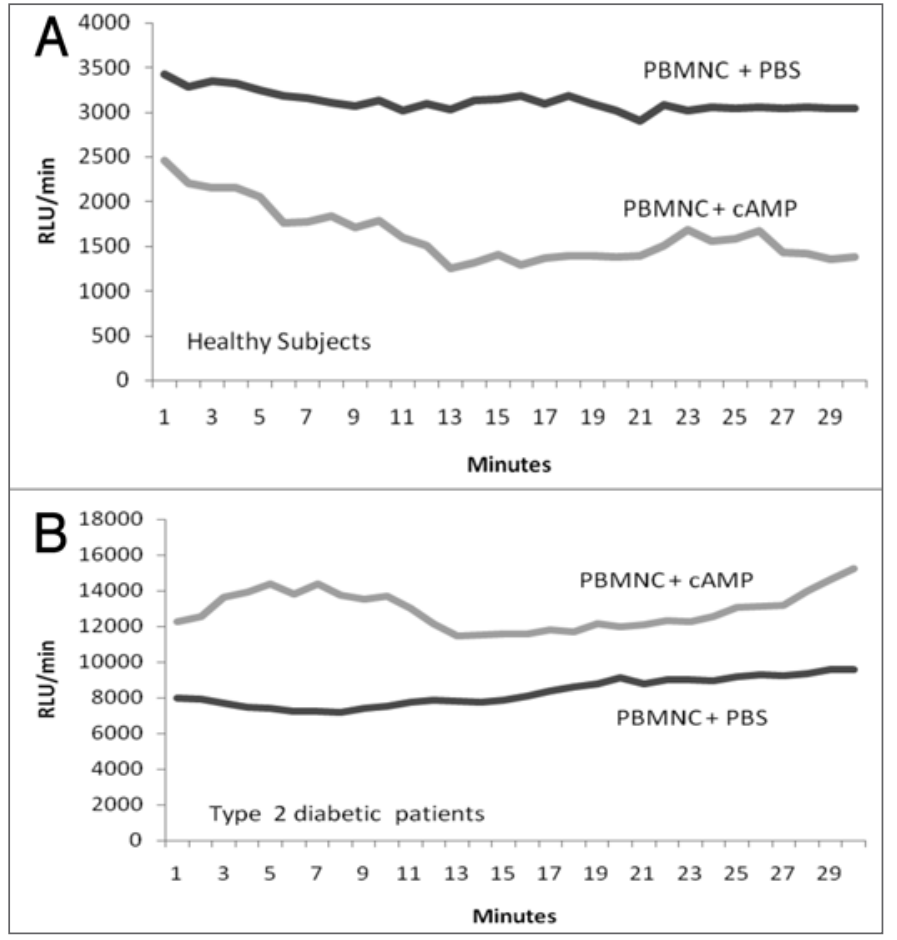

Figure 5. (A and $B$ ) represent typical curves of kinetics studies on reactivie oxygen species (ROS) generation by peripheral blood mononuclear cells (PBMNC) either from healthy control $(A)$ or from type 2 diabetic patients $(B)$ in the presence or in the absence of cyclic AMP (cAMP).

Preparation of peripheral blood mononuclear cells. PBMNC were purified from $10.0 \mathrm{ml}$ of heparinised venous blood using the Ficoll-Hypaque gradient method as described previously. ${ }^{30}$ In the present study, three different densities of Ficoll-Hypaque gradient were employed and three interfaces were formed following centrifugation. The first (upper) interface was rich in mononuclear cells and depleted in granulocytes, whilst the second interface was neutrophil-rich $(100 \%)$, and the third interface was composed of neutrophils $( \pm 95 \%)$ and eosinophils $( \pm 5 \%)$. The cell fraction depleted in granulocytes was employed in the experiments described herein. The viability of cells in all samples was of $>95 \%$ as determined by the Trypan blue exclusion test.

Quantifiation of ROS in peripheral blood mononuclear cells (PBMNC). The generation of ROS was measured quantitatively by chemiluminescence assay using a Magic Lite luminometer, 
Table 3. Correlation between reactive oxygen species (ROS) production and cytokines secretions

\begin{tabular}{ccccc} 
Cytokines & \multicolumn{2}{c}{ ROS production-RLU/min } \\
& Absence of cAMP & \multicolumn{2}{c}{ Presence of cAMP } \\
& ND & DM2 & ND & DM2 \\
& $\mathbf{r}$ & $\mathbf{r}$ & $\mathbf{r}$ & $\mathbf{r}$ \\
\hline IL-6 & -0.039 & 0.130 & -0.442 & -0.340 \\
\hline IFN & 0.373 & -0.088 & -0.138 & -0.416 \\
IL-4 & 0.025 & 0.037 & -0.072 & 0.439 \\
\hline
\end{tabular}

$r=$ represent the coefficient of correlation (Pearson). The secretion of cytokines were evaluated in the presence and in the absence of cyclic AMP. No correlation between ROS production and cytokine releasing was observed. DM2 = Type 2 diabetic patients; ND = healthy control.

(Ciba Corning Co., Medfield, MA, USA). An aliquot (100 $\mu \mathrm{l})$ of phosphate buffer saline (PBS) containing mononuclear cells $\left(1 \times 10^{6}\right)$, previously washed in PBS, was transferred to an unsealed luminescence tube together with $200 \mu \mathrm{l}$ of luminol (dissolved in $0.4 \mathrm{M}$ dimethyl sulphoxide). The final volume was adjusted to $700 \mu \mathrm{l}$ with PBS ( $\mathrm{pH}$ 7.3). Chemiluminescence [expressed in relative light units (RLU)/min] was recorded over a $30 \mathrm{~min}$ period in a control tube. In another tube, ROS production was measured using the same reagents as those in control tube plus a $100 \mu \mathrm{l}$ aliquot of a $10^{-5} \mathrm{M}$ solution of the
cAMP-elevating agent dibutyryl cAMP (dbcAMP; Sigma, St. Louis, MO, USA) and the chemiluminescence was recorded for an additional $30 \mathrm{~min}$.

Determination of cytokines in the supernatant of PBMNC. Aliquots $(200 \mu \mathrm{l})$ of a suspension of PBMNC $\left(1 \times 10^{6} / \mathrm{ml}\right)$ in RPMI-1640 medium were incubated in the presence or absence of dbcAMP $\left(100 \mu \mathrm{L}\right.$ of a $10^{-5} \mathrm{M}$ solution) for $48 \mathrm{~h}$ at $37^{\circ} \mathrm{C}$ under $5 \% \mathrm{CO}_{2}$. Following incubation, the cells were centrifuged and the supernatant collected. The concentrations of IL-4, IL-6 and IFN $\gamma$ were measured by sandwich ELISA using kits supplied by R\&D Systems (Minneapolis, MN, USA) and Assay Designs (Ann Arbor, MI, USA). Plates were read at $450 \mathrm{~nm}$ on an automated ELISA plate reader, and the levels of cytokines were determined by reference to standard curves constructed using recombinant IL-4, IL-6 and IFN $\gamma$.

Statistical analyses. Data were expressed in terms of mean values \pm standard deviations. Comparisons of data between groups were performed with the aid of Origin 6.0 (Microcal Software Inc., Northampton, MA, USA) by using unpaired Student t-tests, analysis of variance (ANOVA) and Pearce correlation analyses. In each case a $\mathrm{p}$ value $<0.05$ was considered to be significant.

\section{Acknowledgements}

This work was supported by grants from FAPEMIG, CNPq and CAPES.

\section{References}

1. Pickup JC. Inflammation and activated innate immunity in the pathogenesis of type 2 diabetes. Diabetes Care 2004; 27:813-23.

2. Ceriello A. New insights on oxidative stress and diabetic complications may lead to a "causal" antioxidant therapy. Diabetes Care 2003; 26:1589-96.

3. Thomas E, Lin YA, Dagher Z, Saha A, Luo Z, Ido Y, et al. Hyperglycemia and insulin resistance: Possible mechanisms. Ann NY Acad Sci 2002; 967:43-51.

4. SrivastavaAK. High glucose-induced activation of protein kinase signaling pathways in vascular smooth muscle cells: a potential role in the pathogenesis of vascular dysfunction in diabetes. Int J Mol Med 2002; 9:85-9.

5. Saitoh M, Nishitoh H, Fujii M, Takeda K, Tobiume $\mathrm{K}$, Sawada Y, et al. Mammalian thioredoxin is a direct inhibitor of apoptosis signal-regulating kinase (ASK) 1. EMBO J 1998; 17:25596-606.

6. Benbernou N, Esnault S, Shin HCK, Fekkar H, Guenounou M. Differential regulation of IFN $\gamma$, IL-10 and inducible nitric oxide synthase in human $\mathrm{T}$ cells by cyclic AMP-dependent signal transduction pathway. Immunology 1997; 91:361-8.

7. Bergamaschi A, Corsi M, Garnier MJ. Synergistic effects of cAMP-dependent signalling pathway and IL-1 on IL-6 production by H19-7/IGF-IR neuronal cells. Cell Signal 2006; 18:1679-84

8. Fasshauer M, Klein J, Lossner U, Paschke R. Interleukin (IL)-6 mRNA expression in stimulated by insulin, isoproterenol, tumour necrosis factor alpha, growth hormone and IL-6 in 3T3-L1 adipocytes. Horm Metab Res 2003; 35:147-52.

9. JakobT, Huspith BN, Latchman YE, Rycroft R, BrostoffJ. Depressed lymphocyte transformation and the role of prostaglandins in atopic dermatitis. Clin Exp Immunol 1990; 70:380-4.

10. Izuora KE, Chase HP, Jackson WE, Coll JR, Osberg IM, Gottlieb PA, et al. Inflammatory markers and diabetic retinopathy in type 1 diabetes. Diabetes Care 2005; 28:714-5.

11. Nishikawa T, Araki E. Impact of mitochondrial ROS production in the pathogenesis of diabetes mellitus and its complications. Antiox Redox Signal 2007; 9:343-53.
12. Lo CJ. Upregulation of cyclooxygenase-II gene and PGE2 production of peritoneal macrophages in diabetic rats. J Surg Res 2005; 125:121-7.

13. Nogueira-Machado JA, cols. Modulation of the production of reactive oxygen species (ROS) by cAMPelevating agents in granulocytes from diabetic patients: an Akt/PKB dependent phenomenon. Diabetes Metab 2006; 32:331-5.

14. Hiramatsu K, Arimori S. Increased superoxide production by mononuclear cells of patients with hypertriglyceridemia and diabetes. Diabetes 1998; 37:832-7.

15. Mohanty P, Hamouda W, Garg RK, Aljada A, Ghanim $\mathrm{H}$, Dandona P. Glucose challenge stimulates reactive oxygen species (ROS) generation by leukocytes. J Clin Endocrinol Metab 2005; 85:2970-3.

16. Cobbs $\mathrm{MH}$, Goldsmith M. How MAP kinases are regulated. J Biol Chem 1995; 270:1483-6.

17. Treiman R. Regulation of transcription by MAPKinases cascades. Curr Opin Cell Biol 1996; 8:205-15.

18. Chio CC, Chang YH, Hsu Ya W, Chi KH, Lin WW. PKA-dependent activation of PKC, p $38^{\text {MAPK }}$ and IKK in macrophage; implication in the induction on inducible nitric oxide synthase and interleukin 6 by dibutyryl cAMP. Cellular Signalling 2004; 16:565-75.

19. Ridley SH, Sarsfiel SJ, Lee JC, Bigg HF, Cawston TE, Taylor DJ. Interleukin-1-induced rat pancreatic islet nitric oxide synthesis require both the p38 and intracellular signal-regulated kinase $1 / 2$ mitogen-activated protein kinases. J Immunol 1997; 158:165-73.

20. Larsen CM, Wadt KAW, Juhl LF, Andersen HU, Karlsen AE, Su MSS. Actions of IL-1 are selectively controlled by p38 mitogen-activated protein kinase: kinase: regulation of prostaglandin $\mathrm{H}$ synthase-2, metalloproteinases and IL-6 at different levels. J Biol Chem 1998; 273:15294-300.

21. Kukidone D, Nishinawa T, Somoda K, Imoto K, Fujisawa K, Yano M, et al. Activation of AMP-activated protein kinase reduces hyperglycemia-induced mitochondrial reactive oxygen species production and promotes mitochondrial biuogenesis in human umbilical vein endothelial cells. Diabetes 2006; 55:120-7.
22. Kelly M, Gauthier MS, Saha AK, Rudeman NB Activation of AMP-activated protein kinases (AMPK) mby interleukin 6 inskletal muscle: association with changes in cAMP, energy states and endogenous fuel mobilization. Diabetes 2009; (ahead of print).

23. Nogueira-Machado JA, Lima e Silva FC, Medina LO, Costa DC, Chaves MM. Modulation of the reactive oxygen species (ROS) generation mediated by cyclic AMP-elevating agents or interleukin 10 in granulocytes from type 2 diabetic patients (NIDDM): a PKAindependent phenomenon. Diabetes Metab 2003; 29:533-7.

24. Betz M, Fox BS. Prostaglandin E2 inhibits production of Th1 lymphokines but not Th2 lymphokines. J Immunol 1991; 146:108-13.

25. Novak TJ, Rothenberg EV. cAMP inhibits induction of interleukin 2 but not interleukin 4 in T cells. Proc Natl Acad Sci USA 1990; 87:9353-7.

26. Glund S, Deshnmukh A, Long YC, Moller T, Koistinen HA, Caidahl K, et al. IL-6 directly increases glucose metabolism in resting human skeletal muscle. Diabetes 2007; 56:1630-7.

27. Tan KS, Nackley AG, Satterfield K, Maixner G, Diatchenko L, Flood PM. Beta(2) adrenergic receptor activation stimulates pro-inflammatory cytokine production in macrophages via PKA and NFkappaBindependent mechanisms. Cell Signal 2007; 19:25160.

28. Mahomed AG, Theron AJ, Anderson R, Feldman C Anti-oxidative effects of theophylline on human neutrophils involves cyclic nucleotides and protein kinase A. Inflammation 1998; 22:545-57.

29. Nogueira-Machado JA, Lima e Silva FC, Cunha PE, Costa DC, Chaves MM. Modulation of the production of reactive oxygen species (ROS) by cAMP-elevating agents in granulocytes from diabetic patients: a Akt/ PKB-dependent phenomenon. Diabetes Metab 2006; 32:331-5.

30. Bicalho HMS, Gontijo CM, Nogueira-Machado JA. A simple technique for simultaneous human leukocyte separation. J Immunol Meth 1981; 40:115-6. 


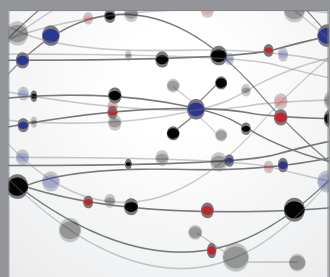

The Scientific World Journal
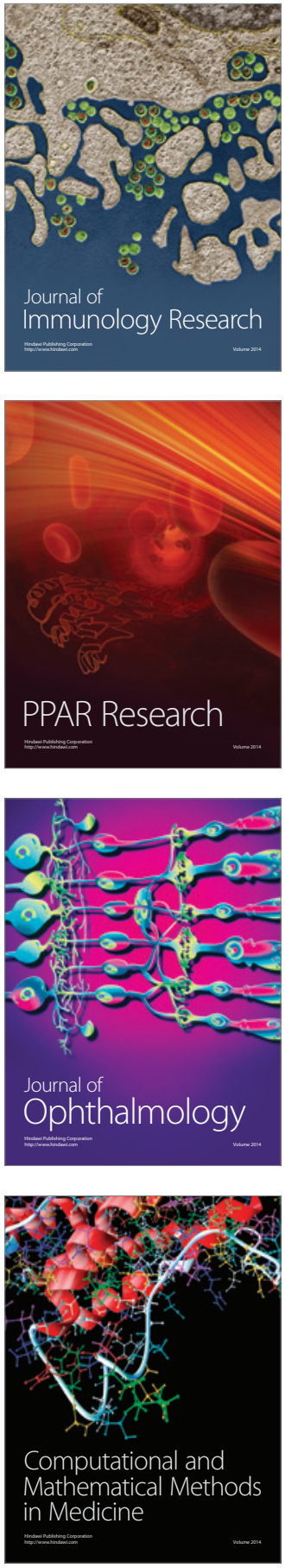

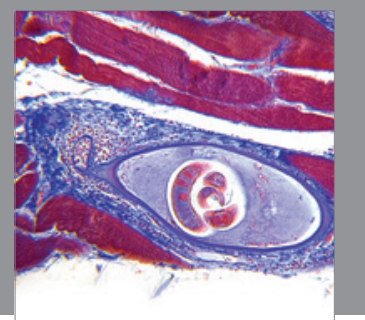

Gastroenterology

Research and Practice
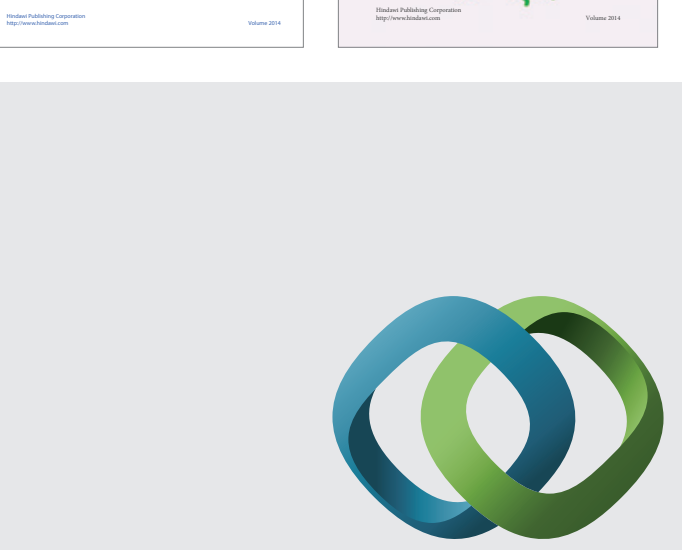

\section{Hindawi}

Submit your manuscripts at

http://www.hindawi.com
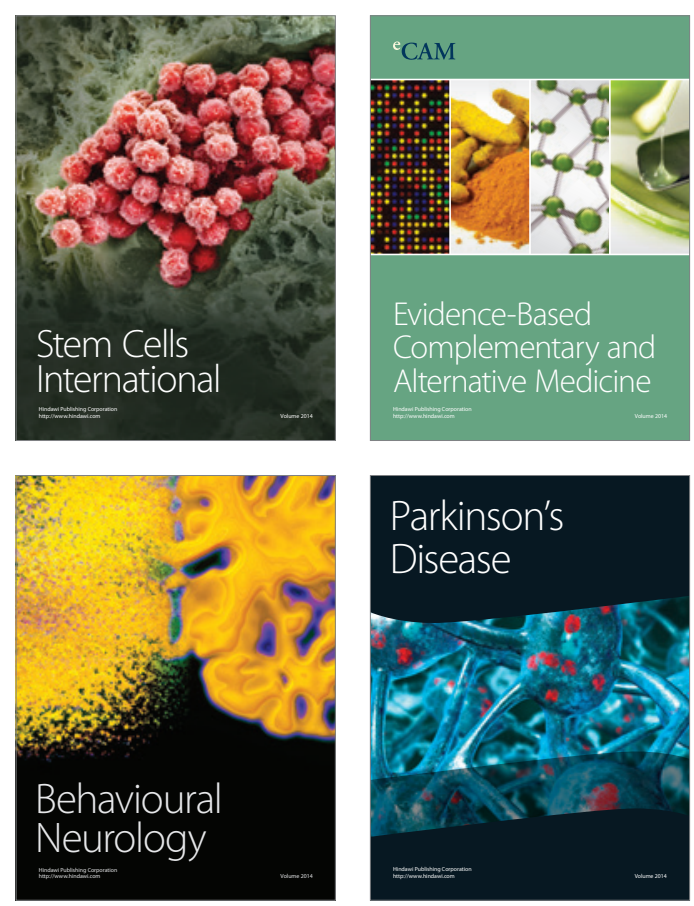

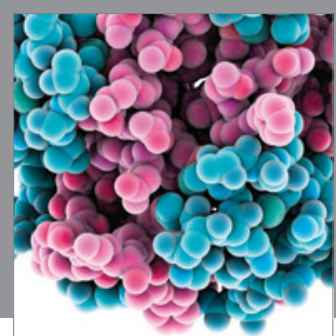

Journal of
Diabetes Research

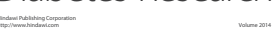

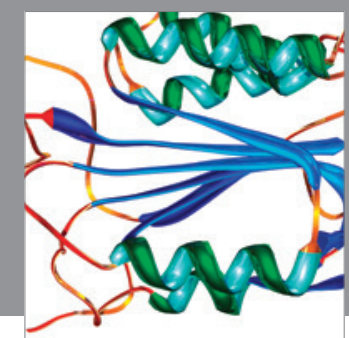

Disease Markers
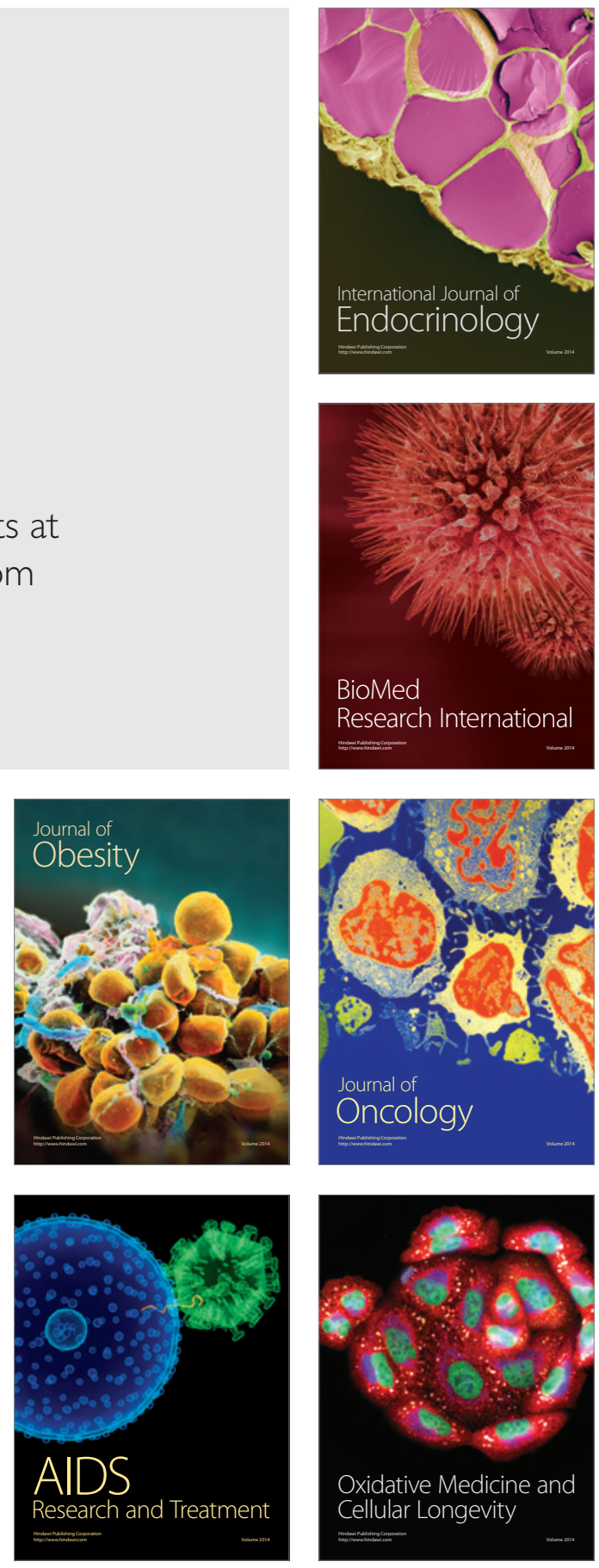